\title{
Sobre os autores / autoras desta edição:
}

\section{Antonio Francisco Perrone Oviedo}

Pós-doutorado em Políticas Públicas e Gestão Ambiental pelo Centro de Desenvolvimento Sustentável (CDS) da Universidade de Brasília (UnB). Doutor pelo CDS/UnB e Mestre em Geografia pela Universidade de São Paulo. Graduado em Ciências Agrárias pela Universidade de Taubaté. Tem experiência na área de Gestão Ambiental, com ênfase em Antropologia Ambiental e Desenvolvimento Rural, atuando nos seguintes temas: pequenos produtores, pescadores artesanais, etnoconhecimento, manejo adaptativo de recursos naturais, gestão de bacias hidrográficas, instrumentos econômicos de gestão ambiental, educação ambiental, monitoramento e avaliação de projetos.

\section{Carlos de Matos Bandeira Júnior}

Mestrando em Ciências da Sociedade / UFOPA. Graduado em Comunicação Social com Habilitação em Publicidade, pelas Faculdades Integradas do Tapajós. Concluinte do Curso de Antropologia na Universidade Federal do Oeste do Pará (UFOPA).

\section{Fábio Gomes de França}

Doutor e Mestre em Sociologia pela Universidade Federal da Paraíba. Bacharel em Segurança Pública pelo Centro de Educação da Polícia Militar do Estado da Paraíba. Pesquisador na área de Sociologia da violência, do poder e do controle social e em temas relacionados à Segurança Pública, Criminologia e Direitos Humanos.

\section{Fernanda Valli Nummer}

Doutorado e Mestrado em Antropologia Social pela Universidade Federal do Rio Grande do Sul. Possui graduação em Ciências Sociais - Bacharelado e Licenciatura - pela Universidade Federal do Rio Grande do Sul. Atualmente é pesquisadora e docente do curso de Graduação em Ciências Sociais da Universidade Federal do Pará. Tem experiência na área de Antropologia e Sociologia, atuando principalmente nos seguintes temas: identidade, sociabilidade, trabalho, militarismo e instituições policiais. 


\section{Isabel Bentes Pereira}

Graduanda em Antropologia pela Universidade Federal do Oeste do Pará.

\section{Marla Elizabeth Almeida Reis}

Mestranda do Programa de Pós-Graduação em Antropologia Social pela Universidade Federal do Amazonas. Graduada em Antropologia pelo Programa de Antropologia e Arqueologia da Universidade Federal do Oeste do Pará (UFOPA). Desenvolve pesquisa na área de Antropologia Econômica, migração, relações de gênero e sociabilidade

\section{Mauro Guilherme Pinheiro Koury}

Possui Graduação em Curso de Bacharelado em Ciências Sociais pela Universidade Federal de Pernambuco (1972), Mestrado em Sociologia pela Universidade Federal de Pernambuco (1976) e Doutorado em Sociologia pela Universidade Federal de São Carlos, SP (2010). É Professor Associado IV da Universidade Federal da Paraíba, lotado no Departamento de Ciências Sociais. É professor do Programa de Pós-Graduação em Antropologia da Universidade Federal da Paraíba (UFPB). Tem experiência na área de Antropologia e Sociologia, com ênfase nas linhas de pesquisas em Sociologia e Antropologia das Emoções; em Sociologia e Antropologia Urbana; e em Sociologia e Antropologia da Imagem e do Visual. Seus trabalhos de pesquisa atuais ligam-se às temáticas: Fotografia e Sociedade, Medos Urbanos, Sociologia e Antropologia Urbana, Cidade e Cotidiano, Sociologia e Antropologia da Imagem e Sociologia e Antropologia das Emoções. Coordena o GREI - Grupo Interdisciplinar de Estudos em Imagem e o GREM Grupo de Pesquisa em Antropologia e Sociologia das Emoções.

\section{Miguel Ângelo Sousa Corrêa}

Possui graduação em Ciências de Defesa Social pelo Instituto de Ensino de Segurança do Pará e graduação em Direito pela Universidade da Amazônia. É especialista em Polícia Comunitária pela UNISUL/SC e mestre em Segurança Pública pela UFPA. Tem experiência na área de Segurança Pública, com ênfase em Polícia Comunitária, bem como, na área de Direito Administrativo Disciplinar e Ciência Penal Militar, aplicados na Comissão de Correição Geral da Corporação. 


\section{Raquel Wiggers}

Possui graduação em Ciências Sociais - Bacharelado pela Universidade Federal de Santa Catarina. Mestrado em Antropologia Social pela Universidade Federal de Santa Catarina. Doutorado em Ciências Sociais pela Universidade Estadual de Campinas. Atualmente é docente do Programa de Pós-Graduação em Antropologia Social e do Programa de Pós-Graduação em Sociedade e Cultura na Amazônia, ambos da Universidade Federal do Amazonas (UFAM). Tem experiência na área de Sociologia Rural e Antropologia Rural tendo estudado transformações no mundo rural, produção de alimentos tradicionais, assentamentos rurais, conhecimentos tradicionais, comunidades e fronteiras identitárias e meio ambiente na Amazônia. Em Antropologia atua com os temas: violência, conflitos domésticos, relações de gênero, abuso e exploração sexual de crianças e adolescentes, parentesco.

\section{Roberth Rodrigues Ferreira}

Possui graduação em Bacharel em Geografia pela Universidade Federal do Oeste do Pará (UFOPA). Tem experiência na área de Geografia, com ênfase em Geografia Agrária, atuando principalmente nos seguintes temas: gênero de vida, conceitos geográficos e território. Atualmente faz Mestrado no Programa de Pós-Graduação Interdisciplinar em Sociedade, Ambiente e Qualidade de Vida (PPGSAQ) na Universidade Federal do Oeste do Pará (UFOPA) trabalhando com as temáticas: sustentabilidade, populações tradicionais, pescadores, conflito de pesca, acordo de pesca, gestão da pesca e manejo comunitário de lagos.

\section{Rubens Elias da Silva}

Doutor e Mestre em Sociologia pelo Programa de Pós Graduação em Sociologia da Universidade Federal da Paraíba. Atualmente é Professor Adjunto do Centro de Formação Interdisciplinar na Universidade Federal do Oeste do Pará (UFOPA). É especialista em sociedades ribeirinhas, com ênfase às populações costeiras e de águas interiores, culturas e práticas sociais. Estuda, também, populações tradicionais na Amazônia, com ênfase em sociabilidades, práticas culturais e relações com o espaço natural: conflitos socioambientais, acordos e gestão dos recursos pesqueiros na Amazônia. Atualmente 
é Professor do quadro permanente no Mestrado em Ciências da Sociedade (abordagem interdisciplinar) e Mestrado em Sociedade, Ambiente e Qualidade de Vida (PPGSAQ) na Universidade Federal do Oeste do Pará.

\section{Solon Pessoa Godinho Neto}

Graduado em Direito pela Universidade Federal do Oeste do Pará. Pós-Graduando em Direito Penal e Criminologia pelo ICPC/UNINTER.

\section{Tiago Silva Alves Muniz}

Mestre em Arqueologia - Museu Nacional - UFRJ. Atualmente é Professor de Arqueologia Pré-Histórica na Universidade Federal do Oeste do Pará. Tem experiência na área de Arqueologia, com ênfase em Arqueologia, atuando principalmente nos seguintes temas: Arqueologia Histórica, Arqueologia Pré-Histórica, Arqueologia Amazônica, Arqueologia da Etnicidade, Análise Cerâmica, Arqueobotânica, Educação Patrimonial, Educação, Ensino-aprendizagem. 